\title{
Modeling Commercial Knowledge to Develop Advanced Agent-based Marketplaces for E-commerce
}

\author{
Martin Molina \\ Department of Artificial Intelligence, Technical University of Madrid \\ Campus de Montegancedo s/n, 28660 Boadilla del Monte (Madrid), Spain \\ Email: mmolina@fi.upm.es
}

\begin{abstract}
This paper argues about the utility of advanced knowledge-based techniques to develop web-based applications that help consumers in finding products within marketplaces in e-commerce. In particular, we describe the idea of model-based approach to develop a shopping agent that dynamically configures a product according to the needs and preferences of customers. Finally, the paper summarizes the advantages provided by this approach.
\end{abstract}

\section{Introduction}

In the knowledge engineering field, a set of methods and techniques has been proposed the last decade to decrease the effort of building large and complex knowledge systems. One of the important ideas of this set of solutions is that it is useful to follow a model-based approach, which can be particularly appropriate in the context of webbased applications. In e-commerce, special kind of software tools conceived as shopping agents [1] are oriented to simulate the behavior of an employee of a company that helps a customer in finding and selecting an appropriate products. Shopping agents are able to perform different specialized tasks such as: customer needs interpretation, product configuration according to the needs, justification of proposals based on utility factors, etc. To carry out these tasks, this type of agents must combine different types of deep knowledge about the commercial relation, which requires a flexible knowledge representation to automatically provide efficient answers and an adequate user-system interaction.

Thus, this paper presents, first, a summary of the concept of model-based development of knowledge systems and, then, the paper presents how this technology can help in building advanced intelligent sales assistants, illustrated with the case of a shopping agent for configurable products. Finally, the paper presents a summary of the advantages provided by the model-based approach for the development of shopping agents.

\section{Model-based development of knowledge-systems}

The model-based approach has been recently followed by different methodologies for system analysis and design. Based on this approach, explicit abstractions about an 
observed system are formulated by using a particular formal representation that facilitates an adequate comprehension of the system architecture and, consequently, an appropriate level of flexibility for maintenance and reuse. In the field of knowledge engineering, a knowledge model can be formulated as an abstraction of the knowledge that an observer (the knowledge engineer) ascribes to a human expert to support a particular problem-solving competence. Some recent methodologies for knowledge system development follow this model-based approach [2,3].

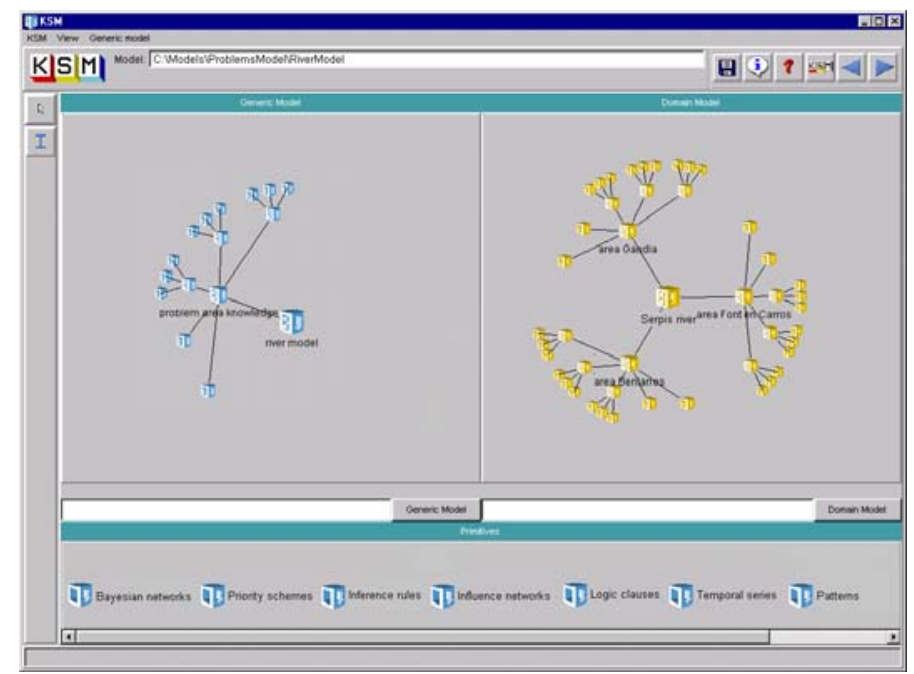

Figure 1: User interface of the KSM software environment for knowledge modeling.

This type of methodologies normally provide a set of abstract description entities based on natural intuitions that capture different epistemological issues better than the traditional view of information processing, using a particular logical level for system description called knowledge level [4]. Entities such as tasks, problem-solving methods, domain ontologies, types of knowledge bases, etc. are normally used in this context. The model-based approach also facilitates the management of abstract reusable designs (conceived as general problem solving methods, PSM) that can be used to guide the development of new applications and, therefore, decrease the effort of knowledge acquisition. Specific software tools such as KSM [5] (figure 1) can facilitate the development of the operational version of such models. The models developed with this tool that can be also combined with an agent-based approach [6]. KSM produces the operational version using knowledge-based software components and help developers and end-users in creating and maintaining complex sets of knowledge bases with different symbolic representations. 


\section{Modeling commercial knowledge of sales assistants}

The analysis of commercial knowledge corresponding to a sales assistant shows the presence of different types of expertise and reasoning processes that need to be adequately structured. In the following, we describe how we applied the recent knowledge modeling approach to produce a final model that support an advanced virtual web-based system for configurable products. Basically, we followed three main phases: (1) analysis of user-system interaction to identify top-level tasks, (2) knowledge-level analysis to formulate a generic model that supports the previous usersystem interaction, and (3) system design at symbolic level to produce the operational version. This section presents a summary of the first and second phases. Information about the third one (symbolic representation) together with an application in the field of photography equipment can be found at [7].

\begin{tabular}{|l|l|l|}
\hline \multicolumn{2}{|l|}{ Type of tasks } & Meaning \\
\hline Acquire customer needs & $\begin{array}{l}\text { Acquisition of the particular customer needs and preferences } \\
\text { according to the type of customer }\end{array}$ \\
\hline Propose product & Global description & Proposal of a candidate product based on the customer needs \\
\cline { 2 - 3 } & Component description & $\begin{array}{l}\text { Detailed description of the proposal, showing components and } \\
\text { technical details }\end{array}$ \\
\cline { 2 - 3 } & $\begin{array}{l}\text { Price of the product and/or } \\
\text { components }\end{array}$ & Total price of the product and price of specific components \\
\hline Justify proposal & $\begin{array}{l}\text { Justification based on needs } \\
\text { satisfaction }\end{array}$ & $\begin{array}{l}\text { Justification explaining how the needs and preferences are } \\
\text { satisfied (in many cases, they are not completely satisfied) }\end{array}$ \\
\cline { 2 - 3 } & $\begin{array}{l}\text { Justification based on quality } \\
\text { factors }\end{array}$ & $\begin{array}{l}\text { Justification explaining the level of the quality of the product } \\
\text { (e.g., consumption, reliability, safety, performance, etc.) }\end{array}$ \\
\cline { 2 - 3 } & Different product & Proposal of an alternative product considering the same needs \\
\cline { 2 - 3 } & Different need & Proposal of an alternative product considering different needs \\
\cline { 2 - 3 } & Different type of component & $\begin{array}{l}\text { Proposal of an alternative product considering a different type of } \\
\text { component }\end{array}$ \\
\cline { 2 - 3 } & Different price or quality & $\begin{array}{l}\text { Proposal of an alternative product considering a different (nor- } \\
\text { mally lower) price or different (normally higher) quality factors }\end{array}$ \\
\hline \multirow{5}{*}{ Compare products } & $\begin{array}{l}\text { Comparison based on needs } \\
\text { satisfaction }\end{array}$ & $\begin{array}{l}\text { Comparative analysis of two products, selecting the better } \\
\text { product from the point of view of the needs satisfaction }\end{array}$ \\
\cline { 2 - 3 } & $\begin{array}{l}\text { Comparison based on price or } \\
\text { quality }\end{array}$ & $\begin{array}{l}\text { Comparative analysis of two products, selecting the product with } \\
\text { better quality or price }\end{array}$ \\
\hline
\end{tabular}

Figure 2: Types of tasks performed by a sales assistant.

The interaction between sales assistant and customer is based on a kind of negotiation process where: (1) the assistant recommends candidate product configurations based on the interpretation of the customer needs (i.e., a successful relation with the customer must be based on the needs instead of the technical details of the product [8]), (2) the assistant must be able of justifying the proposals with convincing explanations, for example, based on utility factors, and (3) the customer must be able of changing (total or partially) the proposals. Figure 2 shows the set of tasks that we identified for a sales assistant according to the previous requirements.

In a second step, we analyzed the commercial knowledge that could provide the previous interaction. Basically, the sales assistant needs to bring together at least three kinds of expertise: (1) knowledge about the products, (2) knowledge about the customer, and (3) knowledge about the company interests. The reasoning process devel- 
oped by the assistant considers different issues from these three different knowledge sources, sometimes combining contradictory criteria that must be solved with additional strategic knowledge. Figure 3 shows a summary of the corresponding types of knowledge to support the tasks identified in the previous section.

\begin{tabular}{|l|l|l|}
\hline Type of knowledge & Category & Meaning \\
\hline Customer types & Customer & $\begin{array}{l}\text { Typical classes of customers organized in hierarchies together with } \\
\text { their characteristics. }\end{array}$ \\
\hline Customer needs & Customer & $\begin{array}{l}\text { Set of needs and preferences of customers together with strategies } \\
\text { for acquiring this information. }\end{array}$ \\
\hline Satisfaction criteria & Customer & $\begin{array}{l}\text { Qualitative levels of customer satisfaction based on need matching } \\
\text { together with actuation strategies. }\end{array}$ \\
\hline $\begin{array}{l}\text { Needs and compo- } \\
\text { nent relations }\end{array}$ & $\begin{array}{l}\text { Customer/ } \\
\text { components }\end{array}$ & Product \\
\hline $\begin{array}{l}\text { Assembly con- } \\
\text { straints }\end{array}$ & Product & $\begin{array}{l}\text { Sets of components in which the product is divided, organized in } \\
\text { families of components. }\end{array}$ \\
\hline $\begin{array}{l}\text { Quality factors of } \\
\text { components } \\
\text { components. }\end{array}$ & Product & $\begin{array}{l}\text { Explicit quality factors (performance, reliability, safety, etc.) of } \\
\text { each component. }\end{array}$ \\
\hline Default components & Product & $\begin{array}{l}\text { Default components to be recommended to customers when there } \\
\text { is not enough information about needs. }\end{array}$ \\
\hline $\begin{array}{l}\text { Catalogues of } \\
\text { products }\end{array}$ & Product & $\begin{array}{l}\text { Database of specific components with specific information about: } \\
\text { price, firm, stock availability, statistics, etc. }\end{array}$ \\
\hline Sales strategies & Company & $\begin{array}{l}\text { Strategies to be applied during the sales process to configure the } \\
\text { final offer by filtering components based on: current stock, mar- } \\
\text { ginal profit, special offers, date, etc. }\end{array}$ \\
\hline Pricing policy & $\begin{array}{l}\text { General criteria to define the final price of the product based on } \\
\text { special offers, type of customer, etc. }\end{array}$ \\
\hline
\end{tabular}

Figure 3: Types of knowledge ascribed to the sales assistant for configurable products.

According to the recent knowledge-engineering methodologies, as it was presented in the previous section, a general knowledge model was formulated as a set of hierarchies of tasks, problem-solving methods and types of knowledge bases. The figure 4 shows a general view of the knowledge model. The figure 4 shows the main global tasks that support the interaction with the customer, associated to the corresponding knowledge models. Figure 4 also shows in more detail the model of one of the main tasks of the sales assistant: configure product. This model is graphically represented as a hierarchy of tasks (circles) and methods (rectangles) with types of knowledge bases (cylinders). The task configure product is carried out by an adaptation of a general artificial intelligence method for design problems, called routine design [9]. The basic idea of this method is to divide the whole design decision in partial classification tasks corresponding to the different components. The whole design is found through a tentative search that proposes hypotheses of design that are rejected when the corresponding design constraints are not satisfied, which forces to backtrack to generate alternative proposals. 


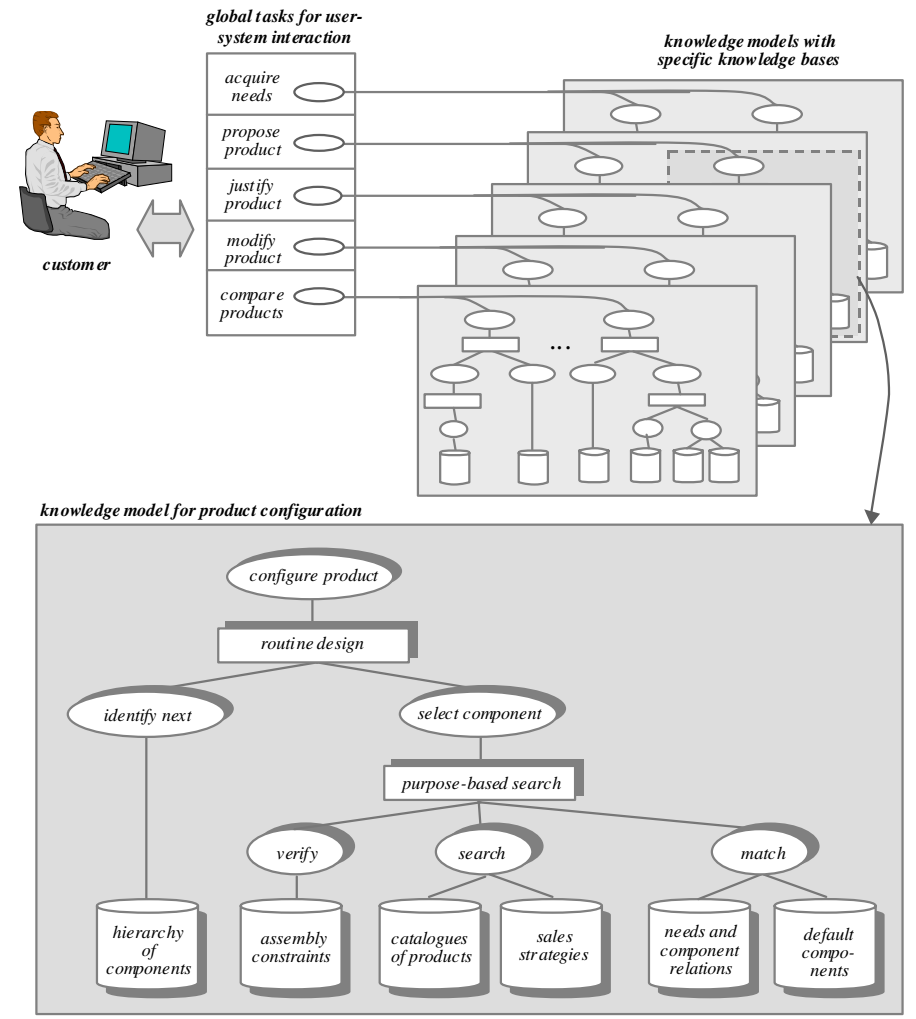

Figure 4: General view of the knowledge organization for the intelligent sales assistant.

\section{Discussion and conclusions}

In summary, the paper shows how the recent advances in the field of knowledge modeling can be applied to develop advanced and complex agent-based systems in ecommerce. In order to cope with the analysis of this knowledge and the implementation of the system, the model-based approach provided the following advantages:

1. Guided knowledge acquisition. The identification of standard classes of tasks (e.g., diagnosis, configuration, classification, etc.) allows developers to use existing knowledge-based patterns that guide the knowledge acquisition process. In the case of sales assistance, the interpretation of customer needs can be viewed as a classification task (to be done, for example, with the heuristic classification method) and the dynamic assembly of components for product configuration is a configuration task (e.g., routine-design method).

2. High level of representation. The knowledge-level concept provides an additional logical level for application formulation. With this, it is possible to identify the cognitive resources of the system without considering symbolic implementation issues, which is useful to formulate the structure and organization of the system before the implementation with more intuitive, natural and abstract terms. 
3. Generic reusable design for different domains. The resulting knowledge model can be abstractly defined using an abstract terminology and types of knowledge bases. Thus, the model is not committed with a specific domain, so it can be reused for different fields. For example, the model described in this paper identifies the knowledge and reasoning processes of a virtual sales assistant for configurable products. But its organization is general, i.e., it can be applied to different domains (e.g., photography equipment, computers configuration, etc.).

4. Advanced software environments for implementation. For the implementation of the model, advanced software environments can be used to help developers in building the final system with the help of knowledge-based software components (e.g., KSM [5]).

The paper presents an innovative knowledge-based model of a virtual assistant that simulates the dynamic configuration of a product according to the interpretation of customer needs. This type of service supposes a significant advance compared to the general tools that can be found in the current marketplaces. The proposed model together with the modeling techniques can be the basis for a new generation of agentbased marketplaces that provides more assistance to customers.

\section{References}

[1] Doorembos R., Etzioni O., Weld D.:”A Scalable Comparison-Shopping Agent for the World Wide Web". Proceedings of the First International Conference on Autonomous Agents. Marina del Rey, California, USA. February, 1997.

[2] Schreiber G., Akkermans H., Anjewierden A., De Hoog R., Shadbolt N., Van de Velde W., Wielinga B.: "Knowledge engineering and management. The CommonKADS methodology” MIT Press, 2000.

[3] Puerta A.R., Tu S.W., Musen M.A.: “Modeling Tasks with Mechanisms”. International Journal of Intelligent Systems, vol 8, 1993.

[4] Newell A.: "The Knowledge Level" In Artificial Intelligence Vol 18 pp 87-127.

[5] Cuena J., Molina M.: "The role of knowledge modelling techniques in software development: a general approach based on a knowledge management tool” International Journal of Human-Computer Studies. No. 52. pp 385-421. Academic Press, 2000.

[6] Molina M., Cuena J.: "Using Knowledge Modelling Tools for Agent-based Systems: The Experience of KSM" in "Knowledge Engineering and Agents Technologies" Cuena J., Demazeau Y., García-Serrano A., Treur J. (eds.) IOS Press, 2001 (in press).

[7] Molina M.: “An Intelligent Sales Assistant for Configurable Products”. Proc. of The First Asia-Pacific Conference on Web Intelligence Maebashi (Japan). Lecture Notes in Artificial Intelligence. Springer Verlag. 2001.

[8] Manning G.L., Reece B.L.: "Selling Today". Prentice-Hall, Inc. A Simon \& Schuster Company. ISBN 0-205-16446-3. 1997.

[9] Brown D., Chandrasekaran B.: "Design Problem-solving: Knowledge Structures and Control Strategies”, Morgan Kaufman, 1989. 